\title{
A EDUCAÇÃo PROFISSIONAL TECNOLÓGICA NA BASE NACIONAL COMUM CURRICULAR: CONCEPÇões E CONTRADIÇÕES
}

\author{
TECHNOLOGICAL PROFESSIONAL EDUCATION IN THE COMMON NATIONAL \\ CURRICULUM BASE: CONCEPTIONS AND CONTRADICTIONS
}

DOI: http://dx.doi.org/10.23926/RPD.2526-2149.2020.v5.n1.p563-581.id618

\author{
Divanez Alves Correia \\ Mestranda em Educação \\ Profissional e Tecnológica \\ (IFTO/Campus Palmas) \\ diapan@gmail.com
}

\section{Jair José Maldaner \\ Doutor em Educação (UnB) \\ Professor do Programa de \\ Mestrado em Educação \\ Profissional e Tecnológica \\ (IFTO/Campus Palmas) \\ jair@ifto.edu.br}

\section{Rivadávia Porto \\ Cavalcante}

Doutora em Linguística

(UFPB)

Professora do Programa de Mestrado em Educação Profissional e Tecnológica, (IFTO/Campus Palmas) riva@ifto.edu.br

\section{Wallysonn Alves de \\ Sousa}

Doutor em Engenharia Elétrica (UNESP)

Professor do Programa de Mestrado em Educação Profissional e Tecnológica, (IFTO/Campus Palmas) wallysonn.sousa@ifto.edu.br
Resumo: Este artigo tem como objetivo analisar e discutir as concepções e contradições constantes na Base Nacional Comum Curricular (BNCC), sobre Educação Profissional Técnica de Nível Médio (EPTNM). Para a realização do estudo procedeu-se criterioso levantamento bibliográfico de cunho teórico sobre a temática em questão. Revisou fontes teóricas sobre educação e EPTNM, formação humanística e currículo integrado na perspectiva da politecnia. Fez-se análise documental da Lei 13.415/2017 e da BNCC, à luz dos aportes do materialismo histórico-dialético enquanto filosofia, teoria e método para a compreensão da realidade, dos conceitos e das contradições envolvendo a EPTNM e sua reconfiguração na atual política de reforma do ensino médio brasileiro. Considerou sua história e a formação técnica integrada na perspectiva omnilateral. Os resultados indicam que, as concepções de EPTNM e sua reconfiguração, no texto da BNCC, ficaram restringidas aos itinerários formativos constatando que, quando se trata da educação integral, há muitas contradições.

Palavras-chave: Educação Profissional Tecnológica; Novo Ensino Médio; Base Nacional Comum Curricular; Formação Integral.

\begin{abstract}
This article aims to analyze and discuss the conceptions and contradictions contained in the National Common Curricular Base-BNCC, on High School Technical Professional Education (EPTNM). In order to carry out the study, a thorough theoretical bibliographic survey about the topic was conducted. Theoretical framework for Education and EPTNM, human development and integrated curriculum from the polytechnic perspective were reviewed. Document analysis, the Law 13.415/2017 and the BNCC, were accomplished in light of the historical-dialectic materialism contributions as a philosophy, theory and method for reality understanding, concepts and contradictions involving EPTNM and its reconfiguration in the current Brazilian policy for high school reform. Its history and integrated technical formation from the omnilateral perspective were considered as well. The results indicate that EPTNM concepts and its reconfiguration in the BNCC text were restricted to the formative itineraries, highlighting that, when it comes to integral education, there are many contradictions.
\end{abstract}

Keywords: Technological Professional Education; New High School; Common National Curricular Base; Integral Formation. 


\section{INTRODUÇÃO}

Com origem dentro de uma perspectiva assistencialista, a Educação Profissional e Tecnológica - EPT, teve seu marco com o decreto 7.566 do presidente Nilo Peçanha, em 23 de setembro de 1909, com o qual, criou as 19 "Escolas de Aprendizes e Artífices”. Em sua trajetória sócio histórica e política, já sofreu várias mudanças. Dentre estas, se destacam avanços, desafios, retrocessos e possibilidades (VIEIRA; SOUZA JUNIOR, 2017).

A partir da criação dos Institutos Federais (IFs) com a Lei n. ${ }^{\circ} 11.741 / 2008$, emergiu uma nova institucionalidade com uma considerável expansão nacional de possibilidades de oferta e de acesso à educação superior, básica, profissional, pluricurriculares e multicampi aos brasileiros. Embora ainda marcada pela dualidade histórica, entre formação básica geral e formação profissional que, por conseguinte, tem motivado disputas políticas e ideológicas em torno de suas concepções.

Os IFs, segundo dispõe o art.39, $\S 2 .^{\circ}$ da lei citada, abrange três categorias de cursos que são ofertados por aquelas instituições, a saber: "I -de formação inicial e continuada ou qualificação profissional; II - de educação profissional técnica de nível médio; III - de educação profissional tecnológica de graduação e pós-graduação" (BRASIL, 2008).

Conforme disposto no texto da lei em pauta, a categoria dos cursos técnicos de nível médio, a qual tomamos como objeto de estudo neste artigo, assume diferentes configurações, quais sejam: a integrada que compreende a formação profissional e o ensino médio em um único curso; a concomitante, que se dá mediante cursos distintos ao mesmo tempo e a subsequente que se refere a um tipo de formação após o término do ensino médio.

Com os movimentos de reforma educacional dos últimos anos, o ensino médio brasileiro foi motivo de muitos debates, disputas políticas e ideológicas em torno de suas concepções e passando por grandes mudanças. A primeira delas ocorreu em 2017, imposta pela Lei 13.415/2017 que alterou a Lei de Diretrizes e Bases da Educação Nacional (LDB 9394/96) e instituiu a política de fomento à implementação de escolas de ensino médio em tempo integral, com a justificativa de melhorar a qualidade do ensino na última etapa da educação básica. A segunda mudança foi a aprovação da Base Nacional Comum Curricular (BNCC) que visa implementar a lei do Novo Ensino Médio orientando um currículo comum para toda a educação básica; além de apontar os conhecimentos a serem construídos, as competências a serem desenvolvidas e as aprendizagens pretendidas para os jovens brasileiros. No entanto, embora apresente pontos positivos nesta direção, há aspectos que apresentam contradições. Por se tratar de uma política pública que tem como finalidade nortear os rumos da educação nacional, nos 
próximos anos, uma análise crítica dos elementos e das proposições que compõem a Lei 13.415/2017 e a BNCC se faz necessária, como forma de avaliar os possíveis impactos favoráveis e/ou (in)satisfatórios desta recente política educacional.

Nesta reforma, as disciplinas ganharam o caráter de componentes curriculares organizadas em áreas do conhecimento; os conteúdos passaram a ser unidades temáticas e o currículo (flexível) organizado mediante a oferta de diferentes "arranjos" curriculares; criou-se a possibilidade de escolha de diferentes caminhos de formação básica e técnica e de contratação de professores com "notório saber" para atuar na formação técnica e profissional.

No que se refere a obrigatoriedade, apenas Língua Portuguesa, Matemática e Língua Inglesa se tornaram compulsórias nos três anos do ensino médio. As demais áreas foram flexibilizadas, ficando à escolha dos alunos podendo ser realizadas ao longo dos três anos; os temas sobre diversidade foram tratados no segmento "arranjos" e podem ser trabalhados como temas transversais.

Considerando o cenário esboçado, o presente artigo visa responder os seguintes questionamentos de pesquisa: quais conceitos de Educação Profissional Técnica de Nível Médio (EPTNM) estão representados nas proposições da BNCC? Tendo em vista que na BNCC, a EPTNM é entendida como itinerário e não como eixo de conhecimento, quais contradições emergem desta proposição?

Com o propósito de dar respostas a estes questionamentos, o presente artigo tem como objetivo analisar e discutir as concepções e contradições da EPTNM constantes da Lei 13.415/2017 e da BNCC, sem deixar de refletir sobre como o teor dos dois documentos influenciam e/ou alteram a organização curricular, as práticas de ensino, bem como a finalidade da educação profissional e tecnológica no contexto de formação humana.

Por isto, fez-se um recorte limitando nossas reflexões às concepções e contradições contidas na Lei 13.415/2017 e na BNCC sobre EPTNM, ora denominada, nestes dois recentes documentos oficiais, de "formação técnica e profissional". Caracterizada como "itinerários formativos", de caráter opcional, os textos em pauta a separa do eixo das áreas de conhecimento, quando um dos grandes desafios na atualidade é proporcionar ao aluno uma formação plena, na perspectiva da politecnia.

Assim posto, a primeira parte do artigo traz uma breve contextualização da EPT no Brasil, de forma geral; a segunda, aborda a educação profissional na BNCC e na Lei 13.415/2017; a terceira traz uma análise documental dos dois documentos referentes à formação 
técnica e profissional e, por fim, na última parte, traz-se as considerações a partir das análises realizadas.

\section{REFERENCIAL TEÓRICO}

\subsection{EduCaÇão Profissional no Brasil: REVisitando trajetórias}

No Brasil, a educação só passou a abranger todas as pessoas no início do século XX diante da necessidade de prepará-las para o mercado de trabalho. Até o século XIX não havia oferta nem experiências sistematizadas de ensino profissional, uma vez que a educação era voltada para a formação das elites dirigentes. As primeiras experiências de educação profissional de forma mais sistematizadas datam de 1809, com a criação do Colégio das Fábricas, pelo príncipe regente, futuro D. João VI (BRASIL, 1999).

A partir do século XX, começam a surgir instituições para atender crianças, pobres e órfãs, com o objetivo principal de retirá-las da rua e dar a elas uma ocupação. As propostas dessas instituições eram direcionadas para o ensino das primeiras letras e a iniciação aos ofícios como a tipografia, a carpintaria, a sapataria, a tornearia, dentre outras (ESCOTT; MORAES, 2012), cujos destinatários eram crianças pobres, órfãs e abandonadas. Daí se conclui que a educação profissional no Brasil tem origem dentro de uma perspectiva assistencialista com o objetivo de amparar os órfãos e os abandonados (RAMOS, 2014, p. 24).

A preocupação com a preparação de operários para o exercício profissional surgiu no século XX quando o presidente Nilo Peçanha cria, em 1909, as Escolas de Aprendizes Artífices, destinadas aos "pobres e humildes", instalando 19 delas em diferentes unidades da federação (RAMOS, 2014, p. 24), sendo que estas, deram origem ou foram transformadas em escolas técnicas estaduais e federais.

Na década de 20, o ensino profissional passou a ser atribuição do Ministério da Agricultura, Indústria e Comércio, como fomento ao desenvolvimento do ensino industrial, comercial e agrícola e com foco numa maior produtividade. Nos anos 30, com o crescimento industrial, surgiu a preocupação e a necessidade de formação de recursos humanos como demanda do processo produtivo. Esse período foi marcado pela criação de novas escolas industriais e introdução de novas especializações nas escolas existentes.

Segundo Ramos (2014, p. 25), os anos 30 e 40, foram marcados por grandes transformações políticas, econômicas e educacionais na sociedade brasileira. As escolas profissionalizantes foram tratadas como um dever do Estado em benefício das classes menos favorecidas e regulamentadas em Leis Orgânicas da Educação Nacional. Neste período, o 
governo Vargas criou o conceito de menor aprendiz consolidando o ensino profissional no Brasil, com o desenvolvimento de ações voltadas para a formação de trabalhadores. Nessa época, surgiu o Sistema "S", com a criação do Serviço Nacional de Aprendizagem Industrial (Senai), seguido do Serviço Nacional de Aprendizagem Comercial (Senac), o Serviço Social do Comércio (Sesc) e o Serviço Social da Indústria (Sesi), impulsionando o atendimento em educação profissional e tecnológica.

É importante ressaltar que nesse período as elites tinham a possibilidade de seguir estudando, enquanto aos menos favorecidos restavam as limitações do ensino profissionalizante. Segundo Kuenzer (2007, p. 27, apud Escott e Moraes, 2012):

[...] a formação de trabalhadores e cidadãos no Brasil, constituiu-se historicamente a partir da categoria dualidade estrutural, uma vez que havia uma nítida demarcação da trajetória educacional dos que iriam desempenhar funções intelectuais e instrumentais, em uma sociedade cujo desenvolvimento das forças produtivas delimitavam claramente a divisão entre capital e trabalho traduzida no taylorismofordismo como ruptura entre as atividades de planejamento e supervisão de um lado, e de execução por outro.

No mesmo sentido, Ramos (2014, p. 25) afirma que:

No momento em que a ideologia do desenvolvimento começava a ocupar espaço na
vida econômica e política do país, sequer houve qualquer preocupação consistente
com o ensino técnico, científico e profissional, oficializando-se o dualismo
configurado por um segmento enciclopédico e preparatório para o ensino superior e
outro profissional independente e restrito em termos da configuração produtiva e
ocupacional.

O processo de industrialização e modernização das relações de produção, exigiram maior qualificação de mão de obra, o que acentuou ainda mais a dualidade entre a formação propedêutica voltada para o ensino superior e a formação instrumental voltada para o mercado de trabalho. Esse quadro foi acentuado durante o Estado Novo pela reforma do ensino secundário realizada pelo ministro Capanema.

Com incentivo nacional e internacional, houve a consolidação da rede de Escolas Técnicas Federais no final dos anos 1950, ocupando lugar estratégico na composição da força de trabalho industrial no Brasil, o que levou a transformação de algumas escolas em Centros Federais de Educação Tecnológica (CEFET), a partir de 1978.

Ramos (2014, p. 29), destaca que "a qualificação de trabalhadores se deu de forma associada aos interesses estrangeiros", sendo criada em 1965 a Equipe de Planejamento do Ensino Médio (EPEM) no âmbito do Ministério da Educação.

Em 1971 a educação passa por uma grande mudança com a aprovação da $\mathrm{n}^{\circ}$ Lei $5.692 / 71$, que reformulou o ensino de $1^{\circ}$ e $2^{\circ}$ graus e impôs a profissionalização compulsória 
em todo o ensino secundário, "com o discurso de atendimento à crescente demanda das classes populares por acesso a níveis mais elevados de escolarização, acarretando, da mesma forma, uma forte pressão pelo aumento de vagas no ensino superior" (ESCOTT; MORAES, 2012).

Vale ressaltar que a compulsoriedade se restringia aos sistemas públicos de ensino, enquanto o sistema privado continuava voltado para a formação propedêutica. Porém, no decorrer dos anos a profissionalização obrigatória perde força e ganha novas proporções com a promulgação da Constituição Federal (CF) de 1988 e a vigência da Lei 9394/96 - nova Lei de Diretrizes e Bases da Educação Nacional.

A partir da CF de 1988 e da Lei de Diretrizes e Bases da Educação Nacional - LDB de 1996, o ensino profissionalizante no Brasil, passa a ocorrer quase que exclusivamente nas Escolas Técnicas Federais - ETF, Escolas Agrotécnicas Federais - EAF e em poucos sistemas estaduais de ensino (ESCOTT; MORAES, 2012). Porém, o debate sobre essa modalidade de ensino continua em pauta no cenário nacional, no sentido de superar a dicotomia entre a educação básica e a educação profissional, que divide o ensino em intelectual e técnico. Segundo Ramos (2014), as discussões aconteceram "sempre à luz da dinâmica do desenvolvimento econômico brasileiro e frente às disputas travadas em torno do projeto societário e, assim, da própria política educacional", principalmente da EPT de nível médio que tem os cursos voltados para o atendimento da demanda do mercado de trabalho.

Dessa forma, a última etapa da educação básica foi e é, historicamente marcada pela separação entre formação básica e formação profissional e motivo de disputas políticas e ideológicas em torno de suas concepções. Os marcos legais, que regem a educação profissional no Brasil, são orientados pela lógica das competências profissionais voltadas para os interesses do mercado, como consta no artigo $5^{\circ}$ das Diretrizes Curriculares Nacionais para a Educação Profissional Técnica de Nível Médio (DCNEPTNM),

Os cursos de Educação Profissional Técnica de Nível Médio têm por finalidade proporcionar ao estudante conhecimentos, saberes e competências profissionais necessários ao exercício profissional e da cidadania, com base nos fundamentos científico-tecnológicos, sócio-históricos e culturais (BRASIL, 2012).

Com essa conotação, entendemos que o conceito de competência nas DCNEPTNM, ganha contornos controversos, por não trazer o trabalho nas suas dimensões ontológica e histórica, mas no sentido de "preparação para o trabalho", marginalizando os conhecimentos científicos do currículo escolar em detrimento dos conhecimentos técnicos. As mudanças implementadas nos últimos anos reforçam, a concepção mercadológica de educação e aprofundam as desigualdades educacionais e, consequentemente, as sociais. 
A Lei 13.415/2017, do Novo Ensino Médio, que instituiu a política de fomento à implementação de escolas de tempo integral ${ }^{1}$, ignorou o caráter mais abrangente da LDB no que diz respeito ao currículo, quando priorizou determinados conhecimentos e desvalorizou outros, como consta nos incisos I e II do parágrafo $8^{\circ}$ do artigo $3^{\circ}$ que modificaram o artigo 35 A da LDB:

\footnotetext{
$\S 8^{\circ}$ Os conteúdos, as metodologias e as formas de avaliação processual e formativa serão organizados nas redes de ensino por meio de atividades teóricas e práticas, provas orais e escritas, seminários, projetos e atividades on-line, de tal forma que ao final do ensino médio o educando demonstre:

I - Domínio dos princípios científicos e tecnológicos que presidem a produção moderna;

II - Conhecimento das formas contemporâneas de linguagem (BRASIL, 2017b).
}

Como podemos observar, muda-se as leis, amplia-se o tempo do aluno na escola, mas no final do Ensino Médio, os estudantes devem demonstrar "domínio de princípios científicostecnológicos da produção moderna e formas contemporâneas de linguagens". Não que essas habilidades não sejam importantes no processo educativo, mas não são suficientes para o desenvolvimento de todas as dimensões da vida humana na perspectiva da politecnia e da formação integral/omnilateral. Nesse sentido há que se perguntar, se a formação humana pretendida pela reforma do ensino médio é mesmo a formação integral dos sujeitos, e como proporcionar tal formação com um currículo mínimo e flexível.

\subsection{A EducaÇão Profissional na Lei 13.415/2017 E NA BNCC}

A Lei ${ }^{\circ} 13.415 / 2017$, que instituiu a política de fomento à implementação de escolas de ensino médio em tempo integral, alterou a LDB e determinou uma série de mudanças na estrutura do ensino médio brasileiro. Segundo o Ministério da Educação e Cultura, as mudanças objetivam "garantir a oferta de educação de qualidade aos jovens e aproximar as escolas da realidade dos alunos, considerando as novas demandas e complexidades do mundo do trabalho e da vida em sociedade" (BRASIL, 2017c).

Dentre as principais mudanças, sobressaem a ampliação do tempo mínimo do aluno na escola de 800 para 1.000 horas anuais; a definição de uma organização curricular flexível, de forma a contemplar uma Base Nacional Comum Curricular (BNCC) e a oferta de diferentes

\footnotetext{
${ }^{1}$ A escola de tempo integral com currículo integral sempre foi, e é, uma luta constante dos movimentos sociais populares e de educadores brasileiros, organizados em sindicatos, associações e fóruns de defesa da escola pública. Portanto a nossa análise e defesa não se refere à escola de tempo integral, mas à escola de currículo integral, para a educação/formação integral.
} 
possibilidades de escolhas de itinerários formativos, com foco nas áreas de conhecimento e na formação técnica e profissional.

No documento desta política, chama atenção o parágrafo $7^{\circ}$ do artigo 35-A. Este, por sua vez, determina que "os currículos do ensino médio deverão considerar a formação integral do aluno, de maneira a adotar um trabalho voltado para a construção de seu projeto de vida e para sua formação nos aspectos físicos, cognitivos e socioemocionais" (BRASIL, 2017b). Redação que é limitada pelos incisos I e II do parágrafo $8^{\circ}$ do mesmo artigo, quando prevê que, ao final do ensino médio o educando deve demonstrar, "I - Domínio dos princípios científicos e tecnológicos que presidem a produção moderna; II - Conhecimento das formas contemporâneas de linguagem" (BRASIL, 2017b).

Os referidos incisos, não englobam a formação humana integral como previsto no parágrafo $7^{\circ}$ do artigo $35-\mathrm{A}$, visto que, para o desenvolvimento pleno na perspectiva politécnica é preciso considerar para além dos princípios científicos e tecnológicos e das formas contemporâneas de linguagem, uma formação humana norteada pelo trabalho, ciência, cultura e tecnologia.

Outra questão que chama a atenção, por contradizer os preceitos da formação integral, é a flexibilização no currículo que deixa como opcionais conteúdos fundamentais para o desenvolvimento dos alunos, tornando obrigatória apenas às disciplinas de Língua Portuguesa, Língua Inglesa e Matemática.

Com relação à formação técnica e profissional, a reforma aprofunda ainda mais a tão discutida e repudiada dicotomia entre formação básica e profissional quando divide o currículo em Base Nacional Comum e itinerários formativos ${ }^{2}$, conforme nova redação dada ao artigo 36 da LDB,

Art. 36. O currículo do ensino médio será composto pela Base Nacional Comum Curricular e por itinerários formativos, que deverão ser organizados por meio da oferta de diferentes arranjos curriculares, conforme a relevância para o contexto local e a possibilidade dos sistemas de ensino, a saber:

I - Linguagens e suas tecnologias;

II - Matemática e suas tecnologias;

III - Ciências da natureza e suas tecnologias;

\footnotetext{
${ }^{2}$ No Brasil, a expressão "itinerário formativo" tem sido tradicionalmente utilizada no âmbito da educação profissional, em referência à maneira como se organizam os sistemas de formação profissional ou, ainda, às formas de acesso às profissões. No entanto, na Lei no 13.415/17, a expressão foi utilizada em referência a itinerários formativos acadêmicos, o que supõe o aprofundamento em uma ou mais áreas curriculares, e também, a itinerários da formação técnica profissional. (BRASIL, 2017a, p. 468).
} 
IV - Ciências humanas e sociais aplicadas;

V - Formação técnica e profissional (BRASIL, 2017b).

Com a implementação dos itinerários formativos, o aluno poderá escolher a área que irá aprofundar seus conhecimentos, se Linguagens e suas Tecnologias; Matemática e suas Tecnologias; Ciência da Natureza e suas Tecnologias; Ciências Humanas e Sociais ou a Formação Técnica e Profissional que, nos Institutos Federais, é ofertada como Educação Profissional e Tecnológica.

A formação, com ênfase técnica profissional e o itinerário integrado, ficam a critério dos sistemas de ensino conforme $\S 3^{\circ}$ do artigo 36 .

$\S 3^{\circ}$ A critério dos sistemas de ensino, poderá ser composto itinerário formativo integrado, que se traduz na composição de componentes curriculares da Base Nacional Comum Curricular - BNCC e dos itinerários formativos, considerando os incisos I a V do caput (BRASIL, 2017b).

Enquanto que, nos cursos de formação continuada de professores, se discute atualização do saber fazer pedagógico vislumbrando o melhoramento da qualidade da educação dos jovens, a Lei 13.415/2017 abre precedentes para que os sistemas públicos de ensino contratem profissionais com "notório saber" voltados para atuar na condução dos itinerários de formação profissional e técnica, conforme disposto no inciso IV acrescidos ao artigo 61

IV - Profissionais com notório saber reconhecido pelos respectivos sistemas de ensino, para ministrar conteúdos de áreas afins à sua formação ou experiência profissional, atestados por titulação específica ou prática de ensino em unidades educacionais da rede pública ou privada ou das corporações privadas em que tenham atuado, exclusivamente para atender ao inciso V do caput do art. 36 (BRASIL, 2017b).

Assim, percebe-se que, com as mudanças propostas, o novo ensino médio não dará conta das garantias e das condições para que se avance na qualidade da educação e nem mesmo da tão sonhada formação integral. Ao contrário disso, regride às políticas implementadas no século passado, onde a educação profissional era voltada somente para o domínio das técnicas de produção e descolada da formação do trabalhador, negando a este, uma formação cidadã e humanizada.

Não obstante, a denominada nova BNCC, aprovada em 2017, surge com a finalidade de implementação da Lei 13.415/2017. Aquela, ressuscita velhos fantasmas em torno do ensino médio integrado. Isto porque, as mudanças nela previstas se configuram retrocesso às conquistas dos últimos anos. Uma das principais alterações que emerge das proposições da BNCC é um novo modelo de interação entre formação geral e formação profissional, proporcionada pela divisão do currículo em cinco itinerários formativos, com obrigatoriedade 
de apenas dois nos três anos do ensino médio, com inclusão de uma opção de formação técnica e profissional.

Centrada no desenvolvimento de competências e orientada pelo princípio da educação integral (BRASIL, 2017a, p. 469), a BNCC está estruturada em dois momentos conforme a Figura 1 a seguir.

Figura 1 - Configuração do Novo Ensino Médio na BNCC

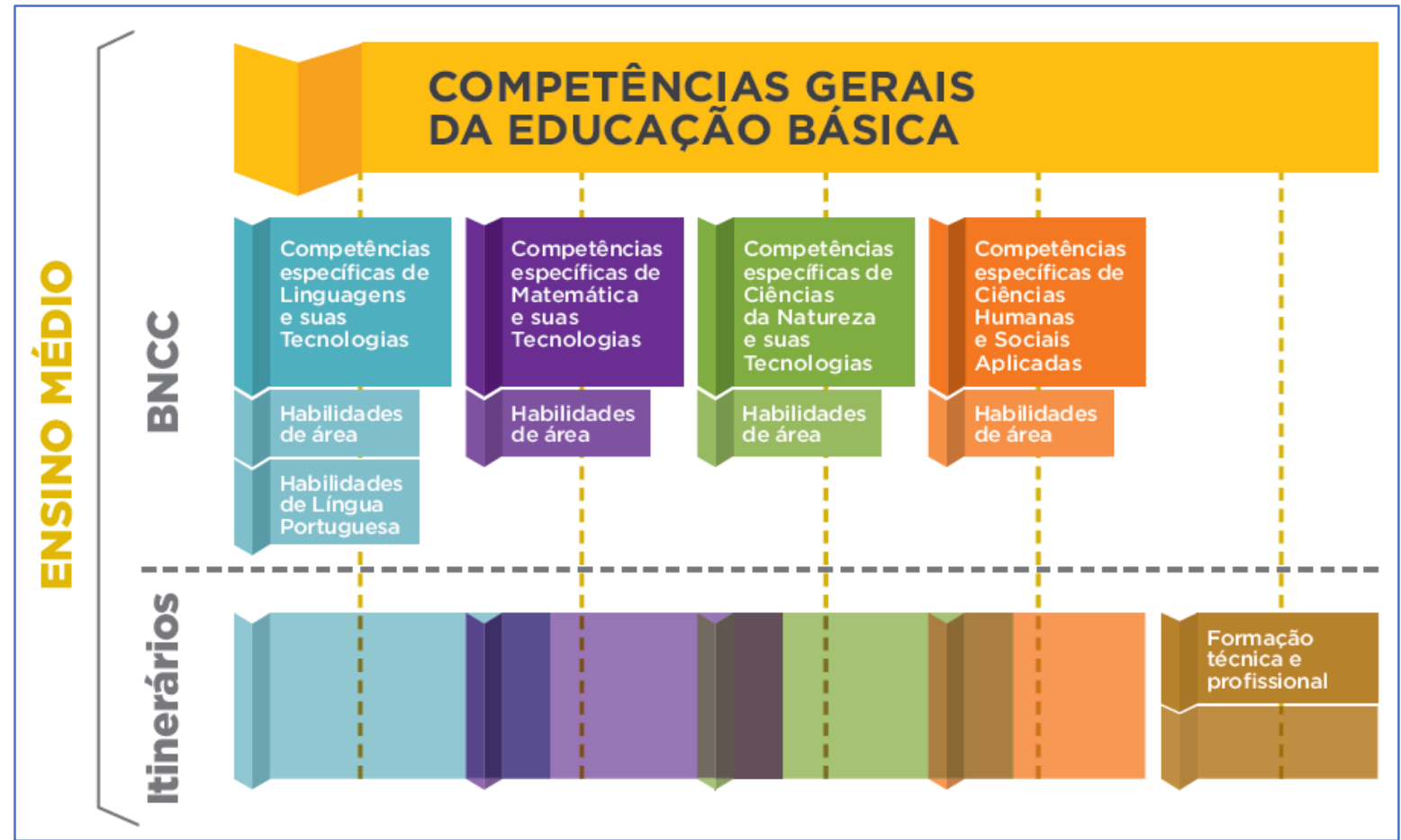

Fonte: (BRASIL, .2017a, p. 469)

Conforme indica a Figura 1, o novo ensino médio, segundo disposições da BNCC, é composto por dois momentos para sua realização. $\mathrm{O}$ primeiro, corresponde às competências específicas de cada área do conhecimento, enquanto que o segundo, aos itinerários formativos. Por seu turno, estes compreendem ao aprofundamento das áreas de conhecimentos e à formação técnica profissional, se os alunos desejarem.

Segundo o serviço de perguntas e respostas - Portal informativo do Ministério da Educação - os itinerários formativos

[...] são o conjunto de disciplinas, projetos, oficinas, núcleos de estudo, entre outras situações de trabalho, que os estudantes poderão escolher no ensino médio e podem se aprofundar nos conhecimentos de uma área do conhecimento e da formação técnica e profissional (FTP) ou mesmo nos conhecimentos de duas ou mais áreas e da FTP. (BRASIL, 2017c).

Diante do exposto, observa-se que a BNCC flexibiliza o currículo apontando para 10 competências gerais definidas como, 
[..] a mobilização de conhecimentos (conceitos e procedimentos), habilidades (práticas, cognitivas e socioemocionais), atitudes e valores para resolver demandas complexas da vida cotidiana, do pleno exercício da cidadania e do mundo do trabalho (BRASIL, 2017a, p. 8),

Ao defender e definir um currículo diversificado e flexível, seus idealizadores afirmam que a nova estrutura,

[...] prevê a oferta de variados itinerários formativos, seja para o aprofundamento acadêmico em uma ou mais áreas do conhecimento, seja para a formação técnica e profissional. Essa estrutura adota a flexibilidade como princípio de organização curricular, o que permite a construção de currículos e propostas pedagógicas que atendam mais adequadamente às especificidades locais e à multiplicidade de interesses dos estudantes, estimulando o exercício do protagonismo juvenil e fortalecendo o desenvolvimento de seus projetos de vida. (BRASIL, 2017a, p. 468).

Os itinerários da formação técnica e profissional é a parte diversificada da formação integral e de escolha dos alunos. O ensino técnico ficou sob a autonomia dos sistemas de ensino tendo como princípio que a formação geral e a técnico-profissionalizante são indissociáveis. Todavia, há controvérsias. Atualmente os estudantes do ensino médio técnico precisam cursar de 2,4 mil horas de formação geral e de 800 a 1,2 mil horas de formação técnica nas formas concomitante, integrado ou subsequente ao regular. Com a reforma, a carga horária foi ampliada, porém, $60 \%$ destinadas aos conteúdo da BNCC e $40 \%$, aos conteúdos optativos e ao longo dos três anos. Dessa forma, em três anos, o aluno poderá ser certificado tanto no ensino médio regular como no curso técnico.

Com as mudanças, cria-se a possibilidade de reabertura para a parceria das redes de ensino com instituições educacionais para a formação técnica, abrindo precedentes para empresas privadas, com financiamento público e fortalecimento do ensino privado como aconteceu com a aprovação da Constituição de 1937 e a Medida Provisória nº 1.549-28 de 1997, que resultou no fortalecimento do ensino privado diminuindo a oferta no sistema público.

\section{DOS ASPECTOS METODOLÓGICOS DO ESTUDO}

Com o propósito de alcançar os objetivos traçados e responder aos questionamentos do estudo, procedeu-se primeiramente um criterioso levantamento bibliográfico de cunho teórico sobre a temática em questão. Revisou fontes teóricas que abordam sobre educação e EPTNM, formação humanística e currículo integrado na perspectiva da politecnia. Em seguida, procedeu-se a análise documental da Lei 13.415/2017 e da BNCC - etapa ensino médio. Momento em que empreendemos leituras e releituras das proposições dos dois documentos buscando evidenciar em suas disposições e proposições quais os conceitos de EPTNM neles 
contidos e quais possíveis contradições emanam desta política voltada para o novo ensino médio.

Para a análise, tomou-se como parâmetro as discussões de estudiosos (SAVIANI, 1989; RAMOS, 2014; ESCOTT; MORAES, 2012; CIAVATTA, 2005; MOURA; FILHO; SILVA, 2015), filiados à corrente de pensamento do materialismo histórico-dialético enquanto filosofia, teoria e método para a compreensão da realidade, dos conceitos e das contradições oriundas dos recentes movimentos de reformas educacionais envolvendo a organização curricular no ensino médio.

Os resultados foram apresentados sob a forma de análise qualitativa mostrando as concepções e contradições da formação técnica profissional a ser realizada pelos sistemas de ensino considerando a formação integral prevista na Lei 13.415/2017 e na BNCC.

\section{Dos Resultados}

Nos últimos anos, dados do Sistema de Avaliação da Educação Básica - SAEB 2017 e do Programa Internacional de Avaliação de Estudantes - PISA 2018³ , que avalia o desempenho dos alunos em Matemática e Língua Portuguesa, têm demonstrado que grande parte dos alunos do ensino médio brasileiro possuem aprendizagem insuficiente.

Com a justificativa de mudar essa realidade, foi criada a Lei 13.415/2017, prevendo o cumprimento da meta 6 do Plano Nacional de Educação (PNE) que visa "oferecer educação em tempo integral em, no mínimo, 50\% (cinquenta por cento) das escolas públicas, de forma a atender, pelo menos, $25 \%$ (vinte e cinco por cento) dos (as) alunos (as) da educação básica" (BRASIL, 2014). Já a BNCC, trouxe o compromisso com a educação integral reconhecendo que a Educação Básica deve visar à formação e ao desenvolvimento humano global, o que significa

[...] assumir uma visão plural, singular e integral da criança, do adolescente, do jovem e do adulto, com a promoção de uma educação voltada ao seu acolhimento, reconhecimento e desenvolvimento pleno, nas suas singularidades e diversidades. (BRASIL, 2017a, p. 14).

No entanto, no que se refere à educação profissional proposta na BNCC, não há garantia do desenvolvimento pleno do aluno, uma vez que o documento aprofunda a histórica

\footnotetext{
${ }^{3}$ A versão preliminar do relatório Brasil no PISA 2018, mostrou que o Brasil ocupa a 70a posição em matemática, entre 79 nações avaliadas e que a média de proficiência dos estudantes brasileiros em Matemática foi de 384 pontos, 108 pontos abaixo da média dos estudantes dos países da OCDE (492). Os 10\% dos estudantes brasileiros com pior desempenho em Matemática no PISA 2018 obtiveram média de proficiência igual a 277, e os 10\% de melhor desempenho, 501 (BRASIL, 2019 - versão preliminar).
} 
contradição entre formação geral básica e formação técnica profissional. No documento em pauta, a primeira deve ocorrer no eixo das áreas de conhecimentos, enquanto que a segunda ficou relegada aos itinerários formativos separada do referido eixo, de caráter opcional e não obrigatória, conforme a representação gráfica da Figura 2.

Figura 2 - Configuração do Novo Ensino Médio na BNCC

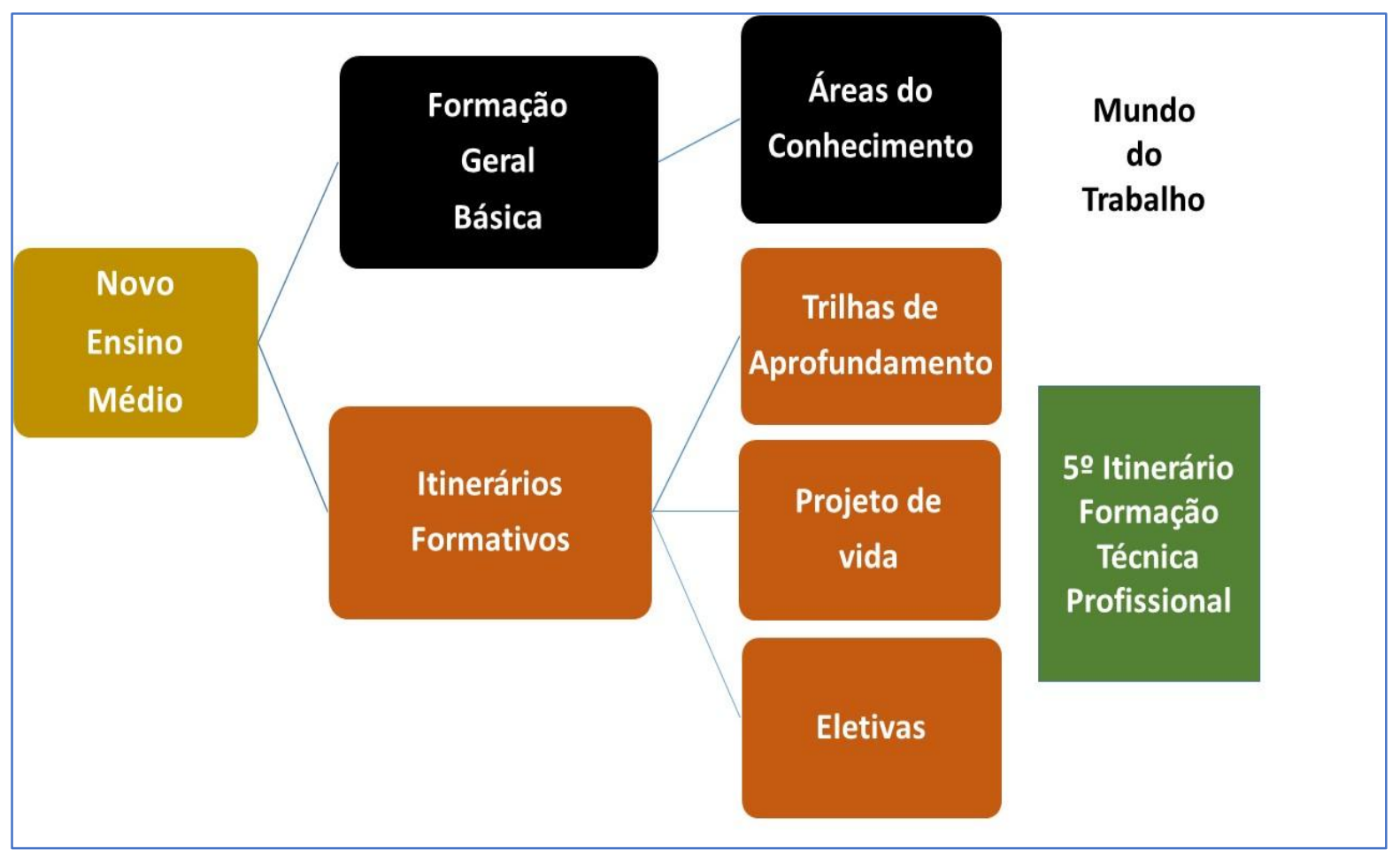

Fonte: Elaboração própria.

Buscando uma reflexão sobre o exposto na Figura 2, alegamos em conformidade com os aportes de Ramos (2014), de que a concepção de educação profissional deve estar comprometida com a formação humana integral. O que na visão da autora, seria uma oportunidade de superar a concepção de "ser humano dividido historicamente" fundada pela força do capitalismo que separa socialmente a força laboral entre quem executa e quem pensa o trabalho e quem dirige ou planeja esta mesma atividade humana. A propósito deste tipo de formação, Ramos traz considerações bastantes pertinentes.

[...] o que se busca é garantir ao adolescente, ao jovem e ao adulto trabalhador o direito a uma formação completa para a leitura do mundo e para a atuação como cidadão pertencente a um país, integrado dignamente à sua sociedade política. (RAMOS, 2014, p. 86).

Na contramão, a BNCC afirma a concepção de educação baseada no desenvolvimento de competências para atendimento ao mercado de trabalho. Impõe à comunidade educacional brasileira a continuidade da luta por um ensino médio técnico que caminhe para a superação da 
histórica separação, entre formação geral e formação específica, mantida por projetos políticos em disputa que, nas palavras de Moura, Filho e Silva (2015, p. 4), "ora sinalizam na direção da formação humana integral e ora a negam em favor dos interesses hegemônicos”. Tais disputas, pelo projeto formativo da classe trabalhadora brasileira ocorrem, segundo os autores, na relação do Estado com a sociedade civil e expressam a mobilização pela disputa de projetos societários.

Assim, considerar demandas, complexidades do mundo do trabalho e da vida em sociedade, na construção de uma política educacional para o ensino médio, nos remete ao conceito de formação integral na perspectiva da politecnia, que segundo Saviani $(1989$, p. 13) caminha "na direção da superação da dicotomia entre trabalho manual e trabalho intelectual, entre instrução profissional e instrução geral”. Devendo, portanto, garantir o domínio das diferentes técnicas que caracterizam o processo de trabalho produtivo.

Todavia, um dos maiores desafios da atual política educacional para a EPTNM, no país, é que ela agudiza a separação, entre formação geral e formação técnica, limitando a classe trabalhadora ao desenvolvimento de competências direcionadas apenas ao atendimento da demanda do mercado de trabalho, conforme representado na Figura 1 e na Figura 2. Logo, as proposições constantes na BNCC trazem uma concepção de formação profissional desvinculada dos conhecimentos gerais, deixando que fique a serviço dos acordos coletivos com empresas, mantendo foco nos setores produtivos e não no desenvolvimento das capacidades do trabalhador. (CIAVATTA, 2005).

No conjunto das mudanças, para além da separação entre a formação geral e a formação específica, observou-se outras contradições, como segue:

a) Tempo integral versus currículo flexível, considerando o compromisso com a educação integral. Na nova configuração, a formação básica geral engloba um conjunto de competências e habilidades das áreas de conhecimentos ${ }^{4}$, com carga horária de 1.800 horas e, os itinerários formativos, incluindo a formação técnica e profissional, são apresentados como o conjunto de situações e atividades educativas opcionais, com carga horária de 1.200 horas.

De fato, há ampliação e distribuição da carga horária, com vistas a implantação da escola em tempo integral. Contudo, o tempo integral não garantirá o desenvolvimento pleno, já que não proporcionará aos alunos um currículo integral, por consequência da flexibilização. Além disso, o aluno pode cumprir a carga horária para a formação técnica dentro da carga horária do

\footnotetext{
${ }^{4}$ Linguagens e suas Tecnologias, Matemática e suas Tecnologias, Ciências da Natureza e suas Tecnologias, Ciências Humanas e Sociais Aplicadas.
} 
ensino regular e, no final dos três anos, terá um diploma do ensino médio e um certificado do ensino técnico, enquanto que nos Institutos Federais, por exemplo, o estudante que opta pelo ensino técnico precisa cursar 1200 horas nas disciplinas específicas e 2400 horas no ensino médio.

Ademais, no antigo ensino médio, todas as disciplinas eram obrigatórias nos três anos de estudo. Com a atual BNCC, apenas Português, Matemática e Inglês tornaram-se disciplinas compulsórias durante as três séries do ensino médio. Enquanto que Filosofia, Sociologia, Arte e Educação Física não ficaram totalmente excluídas, mas não estão necessariamente contempladas, enquanto componentes da organização curricular. Mas podendo serem trabalhadas apenas como temas transversais ou objeto de estudos interdisciplinares.

Outrossim, a flexibilização obriga o currículo mínimo de $60 \%$ na BNCC e os outros $40 \%$ ficam sob a autonomia dos sistemas de ensino em forma de itinerários. As escolas não são obrigadas a oferecer os cinco itinerários, já citados anteriormente, nem mesmo disponibilizar escolha de aprofundamento $\log$ o no $1^{\circ}$ ano.

Com base no exposto, compreende-se que o documento é contraditório, visto que limita o currículo e orienta que a educação integral é um compromisso. Ressalta se aqui que, a proposta de currículo mínimo e fragmentado, conforme orientações da BNCC, não possibilita, educação e formação que proporcionem o desenvolvimento pleno do aluno. Portanto, podemos afirmar que falta na BNCC uma definição conceitual do que é um currículo integral no sentido de garantir educação/formação ampla/integral.

b) Oferta do $5^{\circ}$ itinerário formativo pelos sistemas de ensino e qualidade do ensino ofertado. Desde 2008, os Institutos Federais de Educação, Ciência e Tecnologia têm assumido a responsabilidade pela EPTNM a nível nacional. Estas instituições, durante anos, têm trabalhado, de forma ousada, na busca de inovação de seus modelos formativos destinados a uma educação de qualidade ao público estudantil. Dispõem de laboratórios múltiplos e de um quadro de profissionais com dedicação exclusiva, capacitados para tais finalidades. O mesmo não ocorre com as escolas dos sistemas estaduais e municipais de ensino. Uma grande parte delas estão sucateadas, sem laboratórios, espaço físico adequado, profissionais com formação técnica para atendimento dessa modalidade de ensino e nem mesmo com dedicação exclusiva, entre outros fatores que não corroboram para a oferta de uma formação humana integral. Nesse sentido, compreendemos que a oferta de formação técnica profissionalizante nas redes estaduais e municipais, sem condições próprias e adequadas para tal fim, pode comprometer a qualidade da educação ofertada, gerando um tipo de exclusão social de jovens e de adultos trabalhadores. 
Principalmente no que refere aos seus direitos à formação humana e integral, com qualidade socialmente referenciada prevista no artigo 205 da Constituição Federal de 1988.

c) Formação integral e currículo que, conforme orientações do documento, ao final do ensino médio, o aluno deve demonstrar domínio dos princípios científicos e tecnológicos e conhecimento das formas de linguagem. Entendemos que as linguagens são importantes assim como é o domínio dos princípios científicos e tecnológicos, mas a criticidade é inerente ao ser humano, assim como é o desenvolvimento físico e artístico. Portanto, conceber uma formação sem educação física, artes, filosofia, sociologia, geografia, como obrigação de oferta e direito do aluno, além de outros conhecimentos desenvolvidos no sentido amplo e integrados uns aos outros, é negar de fato aos estudantes, uma formação humana integral.

Compreendemos que ao discutir a educação para o ensino médio, faz-se necessário pensar num currículo para os jovens trabalhadores que todos os anos acessam a escola pública, em busca de conhecimentos e de preparação para a vida e para o trabalho. Assim, não podemos perder de vista que pertencemos a uma sociedade dividida em classes - dominante e dominada, onde quem acessa a escola pública são os jovens de classe dominada, a mercê de uma Constituição liberal democrata garantindo para eles apenas o mínimo. Logo, a escola precisa ser (re)pensada, no sentido da emancipação das pessoas e não no sentido da reprodução dos interesses e da ideologia dominante, aprofundando ainda mais as desigualdades sociais. Assim posto, se queremos uma educação integral, politécnica e omnilateral não podemos confundir educação com treinamento, porque se assim o fizermos, estaremos negando a educação básica, como direito e com qualidade aos trabalhadores e a seus filhos.

\section{CONSIDERAÇÕES FINAIS}

Este artigo teve por objetivo analisar e discutir as concepções e contradições constantes na Lei 13.415/2017 e na BNCC, sobre a EPTNM, o qual levou a perceber que os dois documentos reafirmam a concepção de educação técnica e profissional alicerçada no desenvolvimento de competências para o atendimento à demanda do mercado de trabalho.

Com subsídio do aporte teórico mobilizado foi possível concretizar o objetivo do estudo e responder aos questionamentos de pesquisa.

Da análise observou-se que a formação técnica e profissional, tanto na Lei 13.415/2017 quanto na $\mathrm{BNCC}$, ficou restringida aos itinerários formativos, constatando-se que, quando se trata da educação integral na formação profissional há muitas contradições que emergem das proposições da política de organização curricular materializada na BNCC. 
Dentre as contradições observadas, notamos que, embora o documento traz orientações que visam garantir ao aluno tempo integral na escola, é oportuno enfatizar que elas não garantem um currículo integral para o desenvolvimento de todas as dimensões da vida humana.

Ofertar formação técnica profissional nos sistemas de ensino, sem dúvida alguma ampliará o acesso para aqueles que desejam uma formação técnica para ingresso no mundo do trabalho. Contudo, implementá-la de forma abrupta, nas condições em que se encontram as escolas dos sistemas de ensino, é provável que o acesso não seja acompanhado da tão sonhada qualidade social e muito menos haverá uma formação integral no sentido pleno, uma vez que ficar tempo integral num ambiente que não dispõe de condições adequadas para o acompanhamento pedagógico do aluno, não garantirá o desenvolvimento global do mesmo.

Oferecer educação profissional de forma integral, no sentido de preparar os estudantes para a vida e para o trabalho, significa melhorar a qualidade da educação ofertada, ampliando a estrutura física das escolas, estruturando-as com laboratórios diversos e implementando políticas que proporcionem a superação da dicotomia entre educação profissional e educação geral.

Nossas reflexões se deram em função de entender que a educação básica precisa ser ofertada no sentido de permitir aos trabalhadores compreender o processo produtivo brasileiro e mundial. Para tanto, é fundamental mais do que saber operar as tecnologias de ponta, saber como é que a humanidade evolui ao longo dos anos, e essa compreensão exige a filosofia, a sociologia e todas as áreas do conhecimento como condição fundamental para o desenvolvimento humano. Sem isso, as escolas servirão principalmente para reproduzir o sistema nas suas formas mais desumanas e cruéis.

\section{REFERÊNCIAS}

BRASIL. Base Nacional Comum Curricular (BNCC). Brasília, DF, dez. 2017a. Disponível em: http://basenacionalcomum.mec.gov.br/a-base. Acessado em: 07 de dez. de 2019

BRASIL. Resolucão CNE/CEB no 6, de 20 de setembro de 2012. Define Diretrizes Curriculares Nacionais para a Educação Profissional Técnica de Nível Médio. Brasília, DF, 20 set. 2012. Disponível em:

http://portal.mec.gov.br/index.php?option=com_docman\&view=download\&alias $=11663$ rceb006-12-pdf\&category_slug=setembro-2012-pdf\&Itemid=30192. Acessado em 04 de dez. de 2019.

BRASIL. Lei $\mathbf{n}^{\mathbf{0}}$ 11.892, de 29 de dezembro de 2008. Institui a Rede Federal de Educação Profissional, Científica e Tecnológica. Brasília, DF, 29 dez. 2008. Disponível em: http://www.planalto.gov.br/ccivil_03/_Ato2007-2010/2008/Lei/L11892.htm. Acessado em 04 de dez. de 2019. 
BRASIL. Lei no 13.005, de 25 de junho de 2014. Aprova o Plano Nacional de Educação PNE e dá outras providências. Diário Oficial da União, Brasília, DF, 26 jun. 2014. Disponível em: http://www.planalto.gov.br/ccivil_03/_ato2011-2014/2014/lei/113005.htm. Acessado em 04 de dez. de 2019.

BRASIL. Lei 13.415 de 16 de fevereiro de 2017. Institui a política de fomento à implementação de Escolas de Ensino Médio em tempo integral. Brasília, DF, 16 fev. 2017b. Disponível em: http://www.planalto.gov.br/ccivil_03/_Ato2015-2018/2017/Lei/L13415.htm. Acessado em 04 de dez. de 2019.

BRASIL. Novo Ensino Médio - perguntas e respostas. Ministério da Educação. Brasília, DF, 2017c. Disponível em: http://portal.mec.gov.br/publicacoes-para-professores/30000uncategorised/40361-novo-ensino-medio-duvidas. Acessado em: 20 de dez. de 2019.

BRASIL. Parecer CNE/CEB No 16 de 21 de janeiro de 1999. Trata das Diretrizes Curriculares Nacionais para a Educação Profissional de Nível Técnico. Brasília, DF, 21 jan. 1999. Disponível em: http://portal.mec.gov.br/setec/arquivos/pdf_legislacao/rede/legisla_rede_parecer1699.pdf. Acessado em: 20 de dez. de 2019.

BRASIL. Relatório Brasil no PISA 2018. Versão Preliminar. INEP. Brasília, DF, 2019. Disponível em http://portal.inep.gov.br/acoes-internacionais/pisa/resultados. Acessado em: 27 de dez. de 2019.

BRASIL. Sistema de Avaliação da Educação Básica - Evidências da edição 2017. INEP. Brasília, DF, 2018. Disponível em http://portal.mec.gov.br/. Acessado em: 27 de dez. de 2019.

CIAVATTA, Maria. A formação integrada à escola e o trabalho como lugares de memória e de identidade. Revista Trabalho Necessário, v. 3, n. 3, 2005. Disponível em: https://periodicos.uff.br/trabalhonecessario/article/view/6122. Acesso em: 20 de dez. de 2019.

ESCOTT, Clarice Monteiro; MORAES, Márcia Amaral Correa de. História da educação profissional no Brasil: as políticas públicas e o novo cenário de formação de professores nos institutos federais de educação, ciência e tecnologia. In: IX SEMINÁRIO NACIONAL DE ESTUDOS E PESQUISAS "HISTÓRIA, SOCIEDADE E EDUCAÇÃO NO BRASIL”. Anais... João Pessoa: UFPB, 2012, p. 1492-1508. Disponível em: http://www.histedbr.fe.unicamp.br/acer_histedbr/seminario/seminario9/PDFs/2.51.pdf. Acesso em: 20 de dez. de 2019.

MOURA, Dante Henrique; FILHO, Domingos Leite Lima; SILVA, Mônica Ribeiro. Politecnia e formação integrada: confrontos conceituais, projetos políticos e contradições históricas da educação brasileira. Rev. Bras. Educ. Rio de Janeiro, vol.20, n.63, p. 10571080, 2015. Disponivel em: http://dx.doi.org/10.1590/S1413-24782015206313. Acessado em: 27 de dez. de 2019.

RAMOS, Marise Nogueira. História e política da educação profissional. Curitiba: Instituto Federal do Paraná, 2014. 
SAVIANI, Dermeval. Sobre a concepção de politecnia. Rio de Janeiro: FIOCRUZ. Politécnico da Saúde Joaquim Venâncio, 1989.

VIEIRA, Alboni Marisa Dudeque Pianovski; DE SOUZA JUNIOR, Antonio. A educação profissional no Brasil. Interacções, v. 12, n. 40, 2017. Disponível em:

http://revistas.rcaap.pt/interaccoes/article/view/10691. Acesso em: 20 fev. 2020.

Recebido em: 12 de março de 2019.

Aprovado em: 14 de maio de 2019. 